\section{International Scientific Journal Theoretical \& Applied Science}

\author{
p-ISSN: 2308-4944 (print) e-ISSN: 2409-0085 (online) \\ Year: $2016 \quad$ Issue: 6 Volume: 38
}

Published: $30.06 .2016 \quad$ http://T-Science.org

SECTION 31. Economic research, finance, innovation, and risk management.

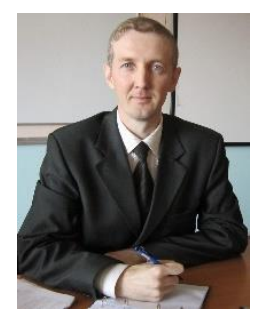

Almir Anfirovich Miniakhmetov Headmaster's assistant, Teacher of Physics, Computer Science and Information Technologies Askino Secondary School №1, Republic of Bashkortostan, Russian Federation minalmir@yandex.ru

Albina Faritovna Malikhova The 2nd years Student of the Faculty of Public Management in the Social Sphere (Master Course), The Bashkir Academy of State Management Service at the Head of the Republic of Bashkortostan, Russian Federation albinainai12010@yandex.ru

\title{
THE STANDARD OF LIVING OF THE POPULATION IN THE RUSSIAN FEDERATION AND ITS SOME GENERAL THEORETICAL ASPECTS OF THE STUDY FOR THE 1ST QUARTER OF 2016
}

\footnotetext{
Abstract: The article deals with general theoretical approaches for determining the statistical characteristics of the level and quality of life in the Russian Federation for the 1st quarter of 2016. There are given factors significantly affecting the quality and standards of living of its citizens. Here is offered some quality of life assessment for all regions of the country and are analyzed statistical standards of living represented by the Federal State Statistics Service of the Russian Federation until March 2016. The article has the examples of the main components of standards of living for the two groups of citizens. Income differentiation is showed as a recommendation of one of the methods of characteristics of the standards of living. The index of income concentration for the 1st quarter of 2016 was calculated and was made a comparison with 2015.

Key words: standard of living, the quality of life, wages, economics, consumer budget, statistics, income, employment, unemployment, differentiation, Gini coefficient.

Language: Russian

Citation: Miniakhmetov AA, Malikhova AF (2016) THE STANDARD OF LIVING OF THE POPULATION IN THE RUSSIAN FEDERATION AND ITS SOME GENERAL THEORETICAL ASPECTS OF THE STUDY FOR THE 1ST QUARTER OF 2016. ISJ Theoretical \& Applied Science, 06 (38): 21-25.

Soi: http://s-o-i.org/1.1/TAS-06-38-5 Doi: crossef http://dx.doi.org/10.15863/TAS.2016.06.38.5
}

УДК 332.12

\section{НЕКОТОРЫЕ ОБЩЕТЕОРЕТИЧЕСКИЕ АСПЕКТЫ ИЗУЧЕНИЯ УРОВНЯ ЖИЗНИ НАСЕЛЕНИЯ РОССИЙСКОЙ ФЕДЕРАЦИИ НА ПЕРВЫЙ КВАРТАЛ 2016 ГОДА}

Аннотация: В статье рассмотрены общие теоретические подходы определения статистических характеристик уровня и качества жизни населения Российской Федерации по состоянию на первый квартал 2016 года. Приведены факторы, существенным образом влияющие на качество и уровень жизни граждан страны. Предложены некоторые показатели оченки качества жизни для любых регионов страны. Проанализированы статистические данные уровня жсизи населения, представленные Федеральной службой государственной статистики Российской Федерации вплоть до марта 2016 года. Показаны примеры основных компонентов стандарта уровня жизни для двух групп граждан. Рекомендован один из методов характеристики уровня жизни - дифференииация доходов населения. Рассчитан индекс концентрациии доходов на первый квартал 2016 года, проведено сравнение с 2015 годом.

Ключевые слова: уровень жизни, качество жизни, заработная плата, экономика, потребительский бюджет, статистика, доходы, занятость, безработица, дифференцииациия, коэффициент Джини.

Статистические методы по изучению уровня и качества жизни населения регионов Российской Федерации являются одной из наиболее важных отраслей экономической статистики [1] как научной дисциплины, так и вида практической деятельности самих органов государственной 
статистики, которая занимается количественной характеристикой массовых явлений и процессов экономики.

С другой стороны, одними из простых показателей количественных изменений экономических явлений, как простых районов республик, так и ведущих регионов Российской Федерации, остаются показатели динамики цен, объема произведенной продукции индивидуальными и частными предпринимателями, численность населения, трудовых ресурсов, уровня безработицы, степени равномерности распределения доходов [2] и других показателей.

Однако, не все данные экономической статистики могут позволить систематическое количественное описание всех основных и ведущих аспектов экономического процесса, экономики Российской Федерации в целом.

Конечно, все статистические показатели необходимы и важны, прежде всего, органам федерального, областного, муниципального управления для решения вопросов, связанных с регулированием экономики региона и разработки дальнейших перспектив еe развития на ближайшее будущее.

В связи с этим, целью данной работы является ознакомление с общими теоретическими методами определения некоторых статистических характеристик уровня жизни населения Российской Федерации по состоянию на первый квартал (до марта месяца) 2016 года.

Согласно [3], те доходы населения, которые обеспечивают личный уровень потребления, определяющим образом влияют на качество и уровень жизни.

Уровень жизни представляет собой степень удовлетворения потребности людей, обеспечивая их жизнедеятельность [4]. Но потребности изменяются в зависимости от личности того, кто представляет эти потребности, общественных условий, в которых они формируются под воздействием разнообразных факторов. Поэтому, само понятие уровня жизни, которое выражается лишь через степень удовлетворения определенных потребностей, является комплексным.

С другой стороны, качество жизни имеет более широкое содержание по сравнению с понятием уровня жизни, хотя оба понятия тесно пересекаются в теории вопроса.

Автор современной книги [5] полагает, что качество жизни выражает степень развития и полноту удовлетворения всего комплекса потребностей и отдельных интересов людей, которые проявляются в жизнеощущении и разных формах деятельности.

В свою очередь, качество жизни также объединяет в себе совокупность всех материальных, социальных, культурных, моральных ценностей, которые позволяют каждому человеку стараться жить в гармонии с обществом, природой, самим собой.

Качество жизни включает в себя еще и состояния экономической, природной, социальной среды общества в целом, отдельного человека, а также духовную сферу его жизни, юридические и политические стороны, связанные с правами и свободами граждан, психологические стороны, идеологию, культурный уровень.

Проблема качества жизни [6] включает в себя положительные и отрицательные условия труда, результат профессиональной деятельности, характер работы согласно профессии, уровень благосостояния семьи, доступ к культурным и социальным ценностям общества, а также демографические, национальные, экологические стороны.

Еще в 80-х годах прошлого столетия, теоретические и практические исследования зарубежных ученых [7] показали, что второстепенное значение имеет состояние здоровья людей, повышение продолжительности жизни, снижение уровня смертности, положительная динамика рождаемости, ослабление степени тяжести заболевания, сокращение длительности болезней, развитие физических и умственных способностей населения, улучшение их общего самочувствия.

Мы полагаем, что для оценки качества жизни каждого региона России важными показателями являются расширение жилых площадей, обустройства жилища, дотация населенных пунктов, повышения прочности, разнообразия одежды и обуви.

Очень действенно на качество жизни влияет состояние образования населения, продолжительность и уровень обучения в социальных институтах, степень овладения научными знаниями, нравственное содержание, художественный уровень российской и зарубежной литературы, доступность физических и электронных библиотек, телевидения в различных режимах вещания, виртуальных музеев и многих других учреждений культуры [8].

Немаловажным фактором влияния на качество жизни являются также улучшение условия труда, развитие инновационного характера профессиональной деятельности, снижение напряженности на рабочем месте, повышение эффективности и обратной качественной отдачи каждого сотрудника, профессиональное соответствие, личных качеств, индивидуальных способностей людей, расширение свободы выбора профессии и специальности. 
Наряду с такими параметрами рабочего труда [9], как длительность рабочего дня (обычно восьмичасовой рабочий день), доля ручного и автоматизированного (или частично автоматизированного), частота и характер производственного травматизма, для каждого человека очень важно моральное удовлетворение, которое приносит непосредственно сам труд, микроклимат в рабочем коллективе, материальная и общественная оценка трудовой деятельности.

Современные исследования [10] показали, что с переходом на рыночные отношения, возросла роль занятости населения и определенные гарантии от безработицы, что, несомненно, является еще одним показателем качества жизни населения. Текущая социальнобытовая обстановка в стране такова, что приходится учитывать уровень преступности, экологическую обстановку, стрессовое напряжение населения определенных регионов в связи с военными, национальными столкновениями или политическими конфликтами, терроризмом в соседних странах, государствах, наркоманией и эпидемиями в пределах обычных регионов страны.

По официальной статистике Федеральной службы государственной статистики Российской Федерации [11], по состоянию на первый квартал 2016 года, уровень жизни населения включает в себя данные об основных показателях денежных доходов, характеризующих объем, состав, основные направления их использования, а также, основные показатели социального обеспечения, социальной помощи населения, жилищный фонд и жилищные условия всех категорий населения.

Анализируя предложенные экономикостатистические данные, мы полагаем, что интерпретация понятия уровня жизни с точки зрения комплексного характера, представляется наиболее подходящей и удобной.

Считаем, что уровень жизни населения Российской Федерации, по состоянию на март месяц 2016 года, определяется как сложная экономическая категория, как некий социальный стандарт, характеризующий степень удовлетворения физических и социальных потребностей граждан практически всех категорий.

Исходя из этого, основными компонентами стандарта уровня жизни россиян остаются здоровье, питание, доходы населения, жилищнокоммунальные условия, домашнее имущество, платные услуги, культурный уровень граждан, условия труда, организация отдыха, социальные гарантии и социальная защита наиболее уязвимых жителей страны.
На основе проведенного анализа подходов к определению и объяснению категории уровня жизни, можно полагать, что первую группу составляют граждане с высоким и достаточным уровнем жизни, в то время, как вторую группу составляют граждане с низким или вообще нулевым уровнем жизни.

В первой группе, в основном, наблюдается практически полное удовлетворение расширенного круга потребностей, а также возможность накапливать определенную долю сбережений.

Во второй группе, согласно анализу, наблюдаются минимальные расходы на товары и услуги, отсутствие возможности удовлетворить минимальные потребности, вплоть до состояния доходов ниже прожиточного минимума.

В тоже время, можно выделить и некое промежуточное звено между обеими группами, так скажем, средний слой населения, в котором проявляются обязательные платежи жилищнокоммунальных услуг, удовлетворение потребностей без дополнительных расходов, однако, без возможности накопления сбережений.

Проведенный анализ благосостояния населения России позволяет более четко разграничить группы граждан в соответствии с определенными признаками, а также расширить понимание тех факторов, которые позволят выявить причины снижения уровня и качества жизни россиян.

В то же время, не следует забывать о том, что уровень жизни населения рассматривается в тесной связи с общими экономическими показателями страны, доходами населения, потребительским спросом, торговлей, ценами и ценообразованием, государственным бюджетом на определенный период, кредитом [12].

Например, доходы населения, являются одним из показателей, связывающий общие экономические показатели страны и уровень жизни граждан, что представляется как ключевой фактор, определяющий уровень жизни людей.

В связи с переходом к рыночным отношениям регионов в России [13], резко обострился процесс расслоения общества, в связи с чем, возникла необходимость использования методов анализа социально-экономической дифференциации населения по денежным доходам, естественно, на основе выборочного обследования бюджетов домашних хозяйств.

Уровень жизни также характеризуется показателями дифференциации материальной обеспеченности населения [14], то есть дифференциации населения по уровню доходов, среди которых особо можно выделить распределение населения по уровню среднедушевых денежных доходов, коэффициент 
дифференциации доходов, индекс концентрации доходов или коэффициент Джини, коэффициент бедности.

Опираясь на проведенные расчеты и анализ результатов авторов [14], можно сказать, что важнейшим методом исследования дифференциации доходов населения является распределение населения по уровню среднедушевых денежных доходов на основе построения вариационных рядов [15] (графическое представление).

Эмпирические данные выборочного обследования бюджетов домашних хозяйств ранжируются и группируются в определенных интервалах по величине дохода. Для статистических характеристик предлагается использовать среднее значение душевого дохода, модальный доход или чаще встречающийся уровень дохода граждан), медианный доход или показатель дохода серединного ранжированного ряда распределения, средний доход или общий средний уровень дохода всего населения.

Полагаем, что модальный и медианный доходя были и остаются одними из важных структурных экономических показателей, которые характеризуют отклонение среднедушевого дохода от среднего значения для из исследуемых групп. Как показал анализ, проведенный нами выше, первая группа населения имеют доход выше среднего, вторая группа, соответственно, ниже среднего.

С учетом того, что в подобного рода статистических исследованиях, наиболее распространенным является децильный коэффициент дифференциации доходов [15] по неравенству в распределении доходов, мы рассчитали отношение минимального дохода у десяти процентов наиболее обеспеченных слоев населения, к максимальному доходу десяти процентов наименее обеспеченных слоев населения.

На основании формул, коэффициент дифференциации доходов рассчитывали путем сопоставления девятого и первого из децилей.

Также были учтены моменты, где функционально очень близким к децильному коэффициенту дифференциации доходов является коэффициент фондов [16], с помощью которого измеряют различие между суммарными или средними значениями доходов десяти процентов наиболее обеспеченной, и десяти процентов наименее обеспеченной части граждан.

Сам индекс концентрации доходов, или коэффициент Джини служит для измерения отличия фактического распределения доходов по численно равным группам граждан от их равномерного распределения или степени неравенства в распределении доходов населения.
Так как коэффициент Джини изменяется в пределах от ноля до единицы, что означает совершенное равенство и совершенное неравенство, то чем ближе индекс к единице, тем выше поляризация доходов в обществе.

Согласно проведенным расчетам в Государственном бюджетном образовательном учреждении Башкирской академии государственной службы управления при главе Республики Башкортостан и данным Федеральной службы государственной статистики Российской Федерации, в 2015 году показатель был в пределах 0,415, однако, по состоянию на март месяц 2016 года, показатель снизился до результата 0,413 .

Это означает, что для таких статистических характеристик уровня жизни граждан, необходимо четко определить и установить границы дохода, которые обеспечивали бы минимально допустимый уровень. Для этого необходимо точное распределение и установление прожиточного минимума, стоимостной оценки минимального набора продовольственных и непродовольственных товаров, обязательные платежи и сборы с населения.

Конечно, коэффициент Джини не единственный индикатор уровня и качества жизни населения. Существует ряд других индикаторов, которые также можно рассчитать статистическими формулами [17].

В любом случае, оценку показателей доходов и уровня жизни составляют следующие экспертно рассчитанные индикаторы: бюджет прожиточного минимума в среднем на душу населения, среднедушевые денежные доходы, среднемесячная номинальная начисленная заработная плата, покупательная способность среднедушевых денежных доходов, коэффициент бедности по доходам, коэффициент Джини.

Таким образом, считаем, что необходимо продолжать исследования качества и уровня жизни граждан как на региональном, так и общероссийском уровне, то есть квалифицированное общественное обсуждение индикаторов их измерения, в том числе в рамках региональной дифференциации.

В свою очередь, данные исследования позволяют лучше интерпретировать реальную ситуацию в стране и отдельных ее регионах, разработать новые теоретические, методологические, методические подходы к изучению качества и уровня жизни населения.

Это способствует разработке новых статистических, социологических методов оценивания индексов, тесного взаимодействия научных достижений и практических результатов. 


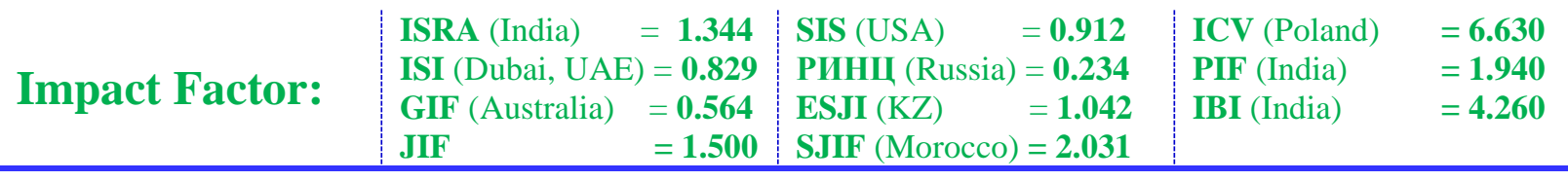

References:

1. Lugueva SN (2014) Statisticheskie metody izuchenija urovnja i kachestva zhizni naselenija. // Aktual'nye voprosy sovremennoj jekonomiki. - Mahachkala: Izdatel'stvo Nekommercheskoe partnerstvo "Dagestanskij territorial'nyj institut professional'nyh buhgalterov", 2014. - №4. pp.442-446.

2. Abakumova NN, Volkova AS (2010) Reformy i novye problemy pensionnoj sistemy. // Idei i idealy. - Novosibirsk: Izdatel'stvo "Novosibirskij gosudarstvennyj tehnicheskij universitet", 2010. - T.2. - №2. - pp.2-8.

3. Prudnikova VV (2009) Privlechennye sredstva chastnyh lic $\mathrm{v}$ bankah Rossii. Statisticheskij analiz. - M.: Izdatel'stvo "Universitetskaja kniga", 2009. - pp.42-57.

4. Blanchard O, Illing G (2009) Makroökonomie. / Pearson Education. - 2009. - pp.313.

5. Zubec AN (2014) Istoki i istorija jekonomicheskogo rosta. - M.: Izdatel'stvo "Jekonomika", - 2014. - 463 p.

6. Zubec AN, Tarba IV (2013) Kachestvo zhizni v Rossii. // Zhurnal "Finansy". - M.: Izdatel'stvo "Knizhnaja redakcija zhurnala "Finansy", 2013. - №12. - pp.51-53.

7. Sandra LB (1987) Gender Schema Theory and Its Implications for Child Development: Raising Gender-Aschematic Children in a Gender-Schematic Society. // Psychology of women: Ongoing debates. - The University of Chicago Press. - Vol.8. - No.4. - 1987. pp.598-616.

8. Vdovina ES, Kopylov AA (2013) Povyshenie kachestva zhizni sel'skogo naselenija vazhnejshij celevoj orientir social'nojekonomicheskogo razvitija Rossii. // Perspektivnye nauki. - Tambov: Izdatel'stvo "Fond razvitija nauki i kul'tury", 2013. №1(40). - pp.96-99.

9. Fajzrahmanova GR (2014) Problema prodolzhitel'nosti rabochego dnja i rabochego vremeni v sovremennyh uslovijah. // Studencheskaja nauka i XXI vek. - JoshkarOla: Izdatel'stvo "Marijskij gosudarstvennyj universitet", 2014. - №11. - pp.157-159.

10. Ljubarec EV (2014) Problema zanjatosti i bezraboticy naselenija v Rossijskoj Federacii. //
Jekonomika i socium. - Saratov: Izdatel'stvo "Institut upravlenija i social'nojekonomicheskogo razvitija", 2014. - №1-2 (10). - pp.198-202.

11. (2016) Uroven' zhizni. Federal'naja sluzhba gosudarstvennoj statistiki Rossijskoj Federacii. Available:

http://www.gks.ru/wps/wcm/connect/rosstat_m ain/rosstat/ru/statistics/population/level/

(Accessed 13.05.2016).

12. Portnova LV, Zolotova LV (2015) Problemy differenciacii naselenija po dohodam i ocenka bednosti naselenija. // Finansy, denezhnoe obrashhenie i kredit: teorija i praktika. Sbornik materialov mezhdunarodnoj nauchnoj $\begin{array}{llll}\text { konferencii. } & - & \text { M.: } & \text { Izdatel'stvo }\end{array}$ "Mezhdunarodnyj centr nauchnoissledovatel'skih proektov", 2015. - pp.52-58.

13. Majorov AI (2014) Investicionnaja politika regiona v rynochnyh otnoshenijah. // XXI vek: itogi proshlogo i problemy nastojashhego pljus. - Penza: Izdatel'stvo "Penzenskij gosudarstvennyj tehnologicheskij universitet", 2014. - №4. - pp.432-436.

14. Suvorov AV, Suhorukova GM, Ivanov VN, Boldov ON, Moiseeva TA (2014) Problemy faktornogo analiza differenciacii dohodov naselenij. // Problemy prognozirovanija. - M.: Izdatel'stvo "Federal'noe gosudarstvennoe bjudzhetnoe uchrezhdenie nauki Institut narodnohozjajstvennogo prognozirovanija Rossijskoj akademii nauk", 2014. - №4. pp.63-83.

15. Il'enkova SD (2004) Mikrojekonomicheskaja statistika. Uchebnik. - M.: Izdatel'stvo "Finansy i statistika", 2004. - 554 pp.

16. Beljaevskij IK (2016) Pokazateli denezhnyh dohodov $\mathrm{i}$ rashodov $\mathrm{v}$ izuchenii urovnja $\mathrm{i}$ kachestva zhizni naselenija Rossii. // Voprosy statistiki. - M.: Izdatel'stvo "Informacionnoizdatel'skij centr "Statistika Rossii", 2016. №2. - pp.57-70.

17. Bobkov VN, Guljugina AA (2015) Monitoring dohodov i urovnja zhizni (1 kv. 2015 g.). // Uroven' zhizni naselenija regionov Rossii. - M.: Izdatel'stvo "Vserossijskij centr urovnja zhizni", 2015. - №2 (196). - pp.100-106. 